\title{
La biblioteca pública como área de oportunidad para los estudiantes de bachillerato
}

Marco Antonio Venegas Medrano

Fecha de recepción: 19 de diciembre de 2019

Fecha de aceptación: 18 de febrero de 2020

\section{Resumen}

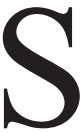

e expone la idea de un "foro abierto" como una de las maneras en que se puede vincular el trabajo cotidiano que se realiza en el aula con las bibliotecas públicas de nuestro país, que ahora se conciben como centros culturales. De esta manera, ciertas actividades académicas pueden llevarse a cabo en estos espacios abiertos a todo público, para que, con ello, exista una relación directa entre el trabajo interno del aula y la ciudadanía en general. El foro abierto al público es una actividad, de entre varias, que se pueden ofrecer a la ciudadanía. Entre otras están las mesas de debate, exposiciones temáticas, conferencias y mesas redondas.

Palabras clave: bibliotecas públicas, debate, pensamiento crítico, argumentación

\section{Introducción}

Las bibliotecas públicas de nuestro país tienen una misión consistente en "Generar las políticas y establecer los procedimientos para facilitar el acceso equitativo, libre y gratuito de los mexicanos al conocimiento y la cultura, y fomentar la lectura en las bibliotecas públicas de la Red Nacional" (Dirección General de Bibliotecas, 2019); asimismo, la visión establecida por la misma red como criterio para el fomento de la cultura en nuestro país, que a la letra dice:

Modernizar la Red Nacional de Bibliotecas Públicas mediante la ampliación de sus servicios, el uso de las nuevas tecnologías, la capacitación de sus bibliotecarios, y la actualización de la normatividad, con el fin de que las bibliotecas públicas del país se conviertan en centros culturales de lectura educativa y recreativa (Dirección General de Bibliotecas, 2019).

En este sentido, la biblioteca pública no sólo tiene la función de facilitar el material bibliográfico requerido por la población demandante, sino que se puede considerar ahora un espacio de difusión de las ideas y expresión de los pensamientos de los jóvenes respecto al mundo que los rodea. Por ello, mi propuesta consiste en vincular el trabajo que se efectúa en el aula con el espacio que ofrecen estos

《 La biblioteca pública se puede considerar un espacio de difusión de las ideas y expresión de los pensamientos de los jóvenes. \ 
nuevos centros culturales en que se están convirtiendo las bibliotecas públicas de nuestro país.

La problemática central del artículo gira en torno a la siguiente pregunta: ¿Pueden las bibliotecas públicas de nuestro país considerarse una plataforma adecuada para abrir la discusión de temas relevantes para la juventud y la sociedad en general, o ésta sólo debería atenderse de forma exclusiva en el interior de un aula? La respuesta que ofreceré a dicha pregunta se decanta por la primera opción, donde ofreceré argumentos para mostrar que los nuevos centros culturales pueden y deben ser considerados como una plataforma abierta al diálogo y al encuentro en una sociedad cada vez más plural, equitativa y abierta, que son precisamente los ejes centrales de la formación de todo ser humano (Bakova, 2012).

\section{Marco general de la propuesta}

Mi propuesta consiste en establecer una estrategia didáctica que vincule el trabajo realizado en clase y las oportunidades que nos brinda la biblioteca pública para abrir los espacios al diálogo con la sociedad, con el fin de formar un tipo de pensamiento que rompa con la inercia de aceptar todo como verdadero, sin lugar para la duda ni la reflexión serena, pero, sobre todo, sin vincularnos activamente con las necesidades sociales de inclusión y equidad. Se trata de un pensamiento crítico que ponga en entredicho las ideas aceptadas como dogma, para construir así una visión más holista, que entienda la realidad de la manera más autónoma posible, en todos los rubros que le atañen a la filosofía: sociedad, moral, humanidad, verdad, conciencia, libertad, muerte, amor, sexualidad, etcétera (Miranda, 2012).

Se parte de la idea central del Modelo Educativo para la Educación Obligatoria (MEPEO) referente a la finalidad del proceso educativo: la finalidad está en contribuir a formar ciudadanos libres, participativos, responsables e informados, capaces de ejercer y defender sus derechos, que participen activamente en la vida social, económica y política de México (sep, 2017b). Esto es, personas que tengan la motivación y capacidad de lograr su desarrollo personal, laboral y familiar, dispuestas a mejorar su entorno social y natural, así como a continuar aprendiendo a lo largo de la vida en un mundo complejo que vive cambios vertiginosos (SEP, 2017a).

《 Los nuevos centros culturales pueden y deben ser considerados

como una plataforma abierta al diálogo

$y$ al encuentro en una sociedad cada vez más plural, equitativa y abierta. $\gg$

La propuesta vincula cuatro criterios fundamentales para la formación de un espíritu crítico: planteamiento de problemas, comprensión clara del alcance de los problemas, respuesta tentativa de los estudiantes y argumentación de tales respuestas (Weston, 2019). Este trabajo hará referencia a estos elementos para forjar el pensamiento sólido en los estudiantes.

\section{La biblioteca pública y los foros abiertos}

A partir de mi experiencia docente, los trabajos que los jóvenes efectúan se reducen sólo a la actividad interna del aula y a la evaluación, aparentemente objetiva, que el profesor lleva a cabo con una matriz de valoración o una rúbrica y elementos semejantes; pero generalmente no existe la posibilidad de mostrar que los mismos pueden funcionar como elementos de difusión de los pensamientos, las inquietudes y hasta las críticas reflexivas de los jóvenes sobre el mundo que los rodea.

El problema central de producir un trabajo interno, y únicamente a nivel interno del aula, es la poca motivación que se produce en los jóvenes en el diseño, el desarrollo y la elaboración de los trabajos exigidos en las materias correspondientes. En mi opinión, la reflexión filosófica no sólo debe darse a nivel conceptual mediante la elaboración de ensayos sobre un tema concreto, sino que requiere el diálogo, el enfrentamiento con otras ideas y la defensa argumentativa de ciertas creencias, entre otros; y eso es importante que se dé, no únicamente con los estudiantes entre sí, sino con la ciudadanía, que, con su experiencia, con su perspectiva, puede ofrecerle al joven una visión más amplia al punto de vista que éste posee por su propia condición; por ejemplo, si la discusión filosófica es en torno al problema de la libertad, la justicia o la 
democracia, bien se puede analizar la perspectiva de un autor o un documento específico, pero nunca tendrá la riqueza que un diálogo abierto puede ofrecer a la perspectiva de los jóvenes (De La Garza, 2011).

Esto me ha motivado a llevar a cabo experiencias de aprendizaje que impliquen exposiciones, mesas de diálogo y debates racionales en las bibliotecas de mi ciudad, específicamente en la biblioteca pública Enrique Fernández Ledesma. Por lo que voy a narrar una de las opciones que he llevado a cabo con mis estudiantes de preparatoria.

Una de las dinámicas realizadas con los jóvenes en estos nuevos foros abiertos al público llevó por título "Foro abierto: los jóvenes hablan", el cual consistió en la presentación de una reflexión personal ante una serie de dilemas éticos y morales actuales. Lo primero que hicieron fue analizar en clase una serie de documentos que explicaran los problemas y el alcance moral que se suscita ante una temática de la vida contemporánea; por ejemplo, el consumismo hedonista, la manipulación de los medios masivos de difusión, el impacto de las redes sociales y el poder mediático del cine, entre otros. Con dichas lecturas, los estudiantes elaboraron unos escritos personales sobre la temática, considerando las propuestas éticas de autores clásicos como Emmanuel Kant, John Stuart Mill, Aristóteles, y modernos como André Comte-Sponville, entre otros. Redactaron alrededor de tres cuartillas donde exponían su punto de vista ante una de las problemáticas ya citadas. Además, los jóvenes elaboraron una presentación en PowerPoint donde se presentaron fotografías, frases, esquemas y gráficas sobre lo que se narraba en su documento escrito.

A partir de lo anterior, durante una semana, guie el trabajo de los jóvenes para que la lectura y la proyección de las diapositivas estuvieran sincronizadas; asimismo, los orienté para mejorar su oratoria en los aspectos de modulación y vocalización. La presentación en la biblioteca consistió en la exposición de su disertación en sincronía con la proyección de las diapositivas, durante un lapso no mayor a cinco minutos. Después de ello, el público presente, es decir, ciudadanos de cualquier nivel educativo o condición social, hizo una serie de preguntas directas a los estudiantes que pudieron responder en un lapso no mayor a siete minutos; de esta forma, cada uno tuvo un total de 12 minutos para la presentación y defensa de su trabajo. El foro contó con la participación de siete estudiantes; su duración fue de 1 hora y 30 minutos aproximadamente.

Un aspecto muy importante para motivar a los jóvenes a salir de su claustro y presentarse ante el público fue el trabajo de difusión que la biblioteca hizo mediante la elaboración de carteles, en los cuales se presentaba hora y fecha del foro abierto, así como las fotografías de los mismos estudiantes en dichos carteles. Por otra parte, los entusiasmó la idea de que, incluso, sus propios padres podrían estar presentes en el foro. En mi

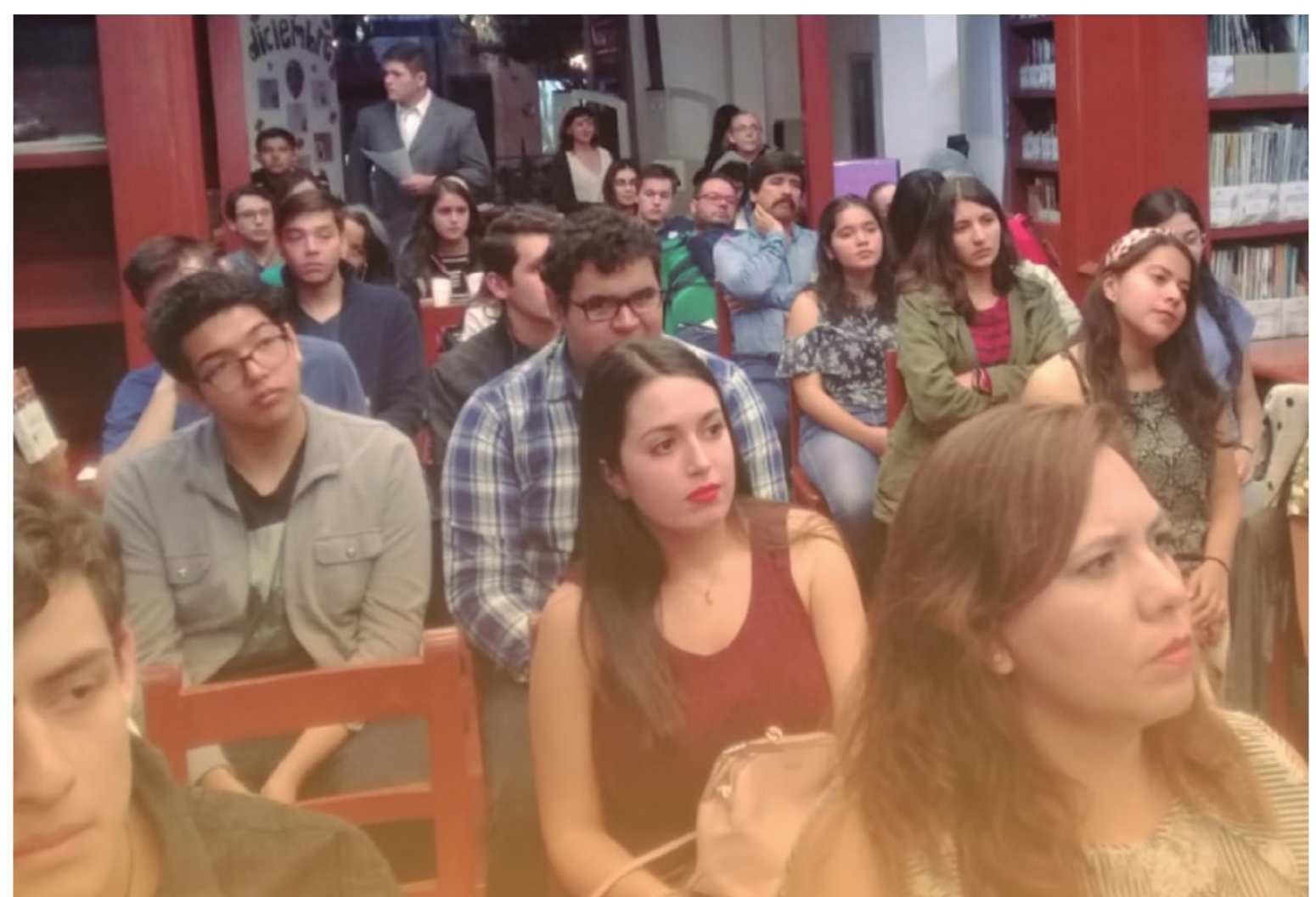


papel de profesor, hice un trabajo de vinculación con la dirección de la biblioteca para ofrecer café y galletas al final del foro; eso le dio un ambiente formal, pero al mismo tiempo libre. La gestión que hice implicó, además, solicitar el espacio de la biblioteca y gestionar la elaboración y distribución de los carteles para la difusión del foro. Cabe destacar que la experiencia fue muy grata para los jóvenes, pues se percataron que sus propias producciones, es decir, sus ideas, pueden ser escuchadas y valoradas más allá de las limitantes del aula.

En este sentido, uno de los estudiantes, quien presentó el trabajo titulado "La violencia contra los ancianos y discapacitados", aseguró: "nunca me imaginé que mi propuesta pudiera provocar preguntas en el público" (Entrevistado 1, comunicación personal, 4 de diciembre de 2019). Asimismo, otra estudiante, quien participó con la propuesta titulada "Crueldad animal", comentó: "al principio te pones nerviosa, pero luego tomas el hilo y te sigues. Me gustó saber que a mucha gente le importa lo que hacemos mal a los animales" (Entrevistada 2, comunicación personal, 4 de diciembre de 2019).

《 La finalidad del proceso educativo está en contribuir a formar ciudadanos libres, participativos, responsables e informados, capaces de ejercer y defender

sus derechos, que participen activamente en la vida social, económica y política de México. $\gg$

\section{Conclusiones}

Con el desarrollo de esta actividad he llegado a dos conclusiones. La primera es que los estudiantes se encuentran muy dispuestos a participar en actividades que los coloquen fuera de lo cotidiano. Hubo un interés marcado por presentar una propuesta de calidad, así que la preparación previa al foro fue
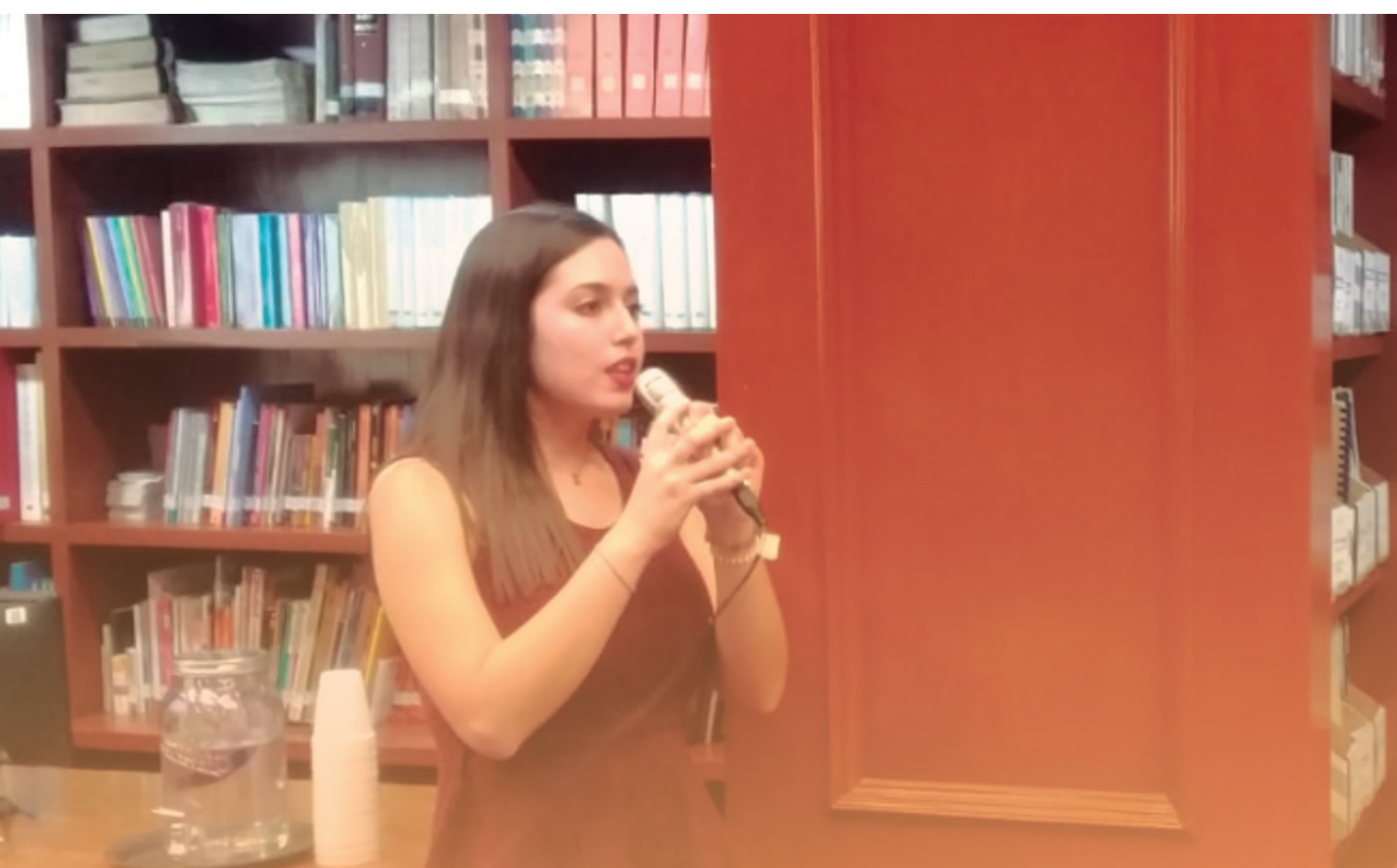
